\title{
Early Warning on Disastrous Weather through Cell Phone
}

\author{
Md. Rokon Uddin ${ }^{1}$, M Abdul Awal ${ }^{2}$ \\ ${ }^{I}$ (Department of Electrical Engineering \& Computer Science, North South University, Bangladesh) \\ ${ }^{2}$ (Department of Electrical Engineering \& Computer Science, North South University, Bangladesh)
}

\begin{abstract}
This paper proposed a Weather Early Warning system for minimizing human life loss in natural disasters like tsunami, cyclone, tornado etc. The proposed system is a value added service which can be provided by telecomm operators to their subscribers. The proposed system alerts the subscribers through phone call and SMS depending on the weather condition of their locations.
\end{abstract}

Keywords - Weather early warning, natural disaster pre-caution, value added service, weather api, weather server.

\section{INTRODUCTION}

Natural disaster leads to financial, environmental or human losses. The resulting loss depends on the vulnerability of the affected population to resist the hazard, also called their resilience. Every year so many people die because of the natural disasters like cyclone, tornado, tsunami etc. In Bangladesh most of the people die during natural disasters just because of the lack of weather information in advance. Almost every people, at least every family in our country has one mobile phone. So if it is possible to alert them early about a cyclone, tornado, tsunami etc, it will be very helpful for them to save their lives. To do this we are proposing a weather early warning system which is a value added service and available for subscription for any mobile device. This system will alert the subscribers about weather condition via SMS or phone calls.

This paper is organized as follows: Section II provides discussion of several research works. Section III describes our proposed early warning system. Section IV provides feasibility and performance analysis of the proposed early warning system. Section V discusses about the future opportunities of the system. Finally, section VI concludes the paper.

\section{RELATED WORKS}

There several researches are happing worldwide because natural disasters are one of the major concerns about human existences. For example, Chanuka Wattegama [1] discussed briefly about what Information and Communication Technology (ICT) can do for disaster management. Technology is being updated day by day. There exist high-tech equipments which can collect data from various sources and predict about future disasters. ICT is the most important sector in disaster management. Dr. Mashury Wahab et al. [2] described their disaster early warning system where data are collected from several source, compiled and stored in the database and warns the subscriber through SMS, E-mail, Broadcasting systems. Olaf Neussner [3] described an early alert system named LFEWS (Local Flood Early Warning System) which consists of several components like rain and river level gauges, operation center where data are received, analyzed and decisions about a warning are taken. It also informs about evacuation route, evacuation centers and emergency rescue teams. In [4], Joko Windarto proposed a flood early warning system which uses artificial neural network for predicting future disaster. This system warns the people through SMS and web. In [5], the multi-hazard early warning system of Shanghai is briefly described. Brendan Williams [6] proposed some technologically advanced modifications to Queensland Early Warning System. P. Vanderkimpen et al. [7] proposed a flood early warning system for Egypt which consists of several components, which are automatically activated and linked. These components are rainfall forecasting model (Weather Research and Forecast model), customized hydrological model (to reflect arid region conditions), hydraulic model (InfoWorks-RS) and a warning module (FloodWorks). It sends alerts by email or SMS or web. In [8], Kerry Plowright briefly described global multihazard early warning system of Australia. This multi-hazard and multi-channel geographic early warning system is designed to broadcast alerts instantly and simultaneously to individuals or groups in the selected areas. These alerts or notifications are sent through multiple communication mediums like SMS, phone call, email, desktop alert etc. Chai Mui Fatt et al. [9] described briefly about Tsunami early warning system in Malaysia and created a Tsunami database for implementation of the plan of Regional Tsunami Watch Providers (RTWP). In [10-14], authors also analyze disaster early warning systems of Malaysia, discuss the risks and provide solutions through the implementation of various technologies. These solutions are using various hardware, processors, sensors etc for collecting data and taking decisions (sometimes by using artificial intelligence) which will be costly for the 
developing country like Bangladesh. For this reason we are proposing a low cost and user friendly early warning solution for the people of Bangladesh.

\section{Proposed Weather EARLY WARNing SySTEM For BangladeSh}

Bangladesh geographically is in a place where several natural disasters like cyclone, tsunami, tornado etc are happening every year. Several disasters are happing in the whole world because of climate changes which are shown in Fig. 1.

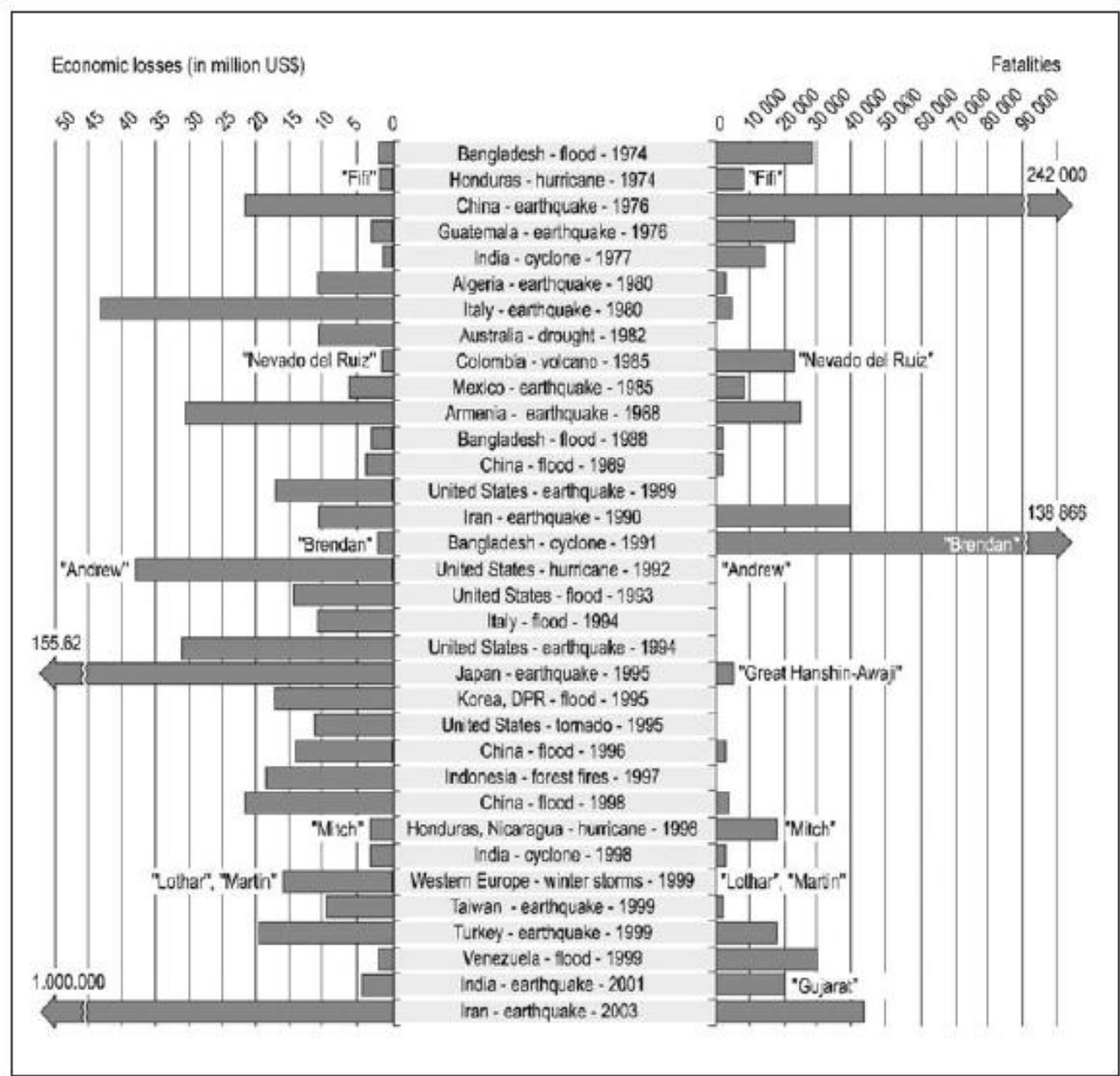

Fig. 1 Large-Impact Disasters over the Last 30 Years [15]

In our country, every year so many people are dying during natural disasters because of not getting early alerts in the right time. There are several entities that are responsible for sending alerts:

1) Local communities

2) Local governments

3) National governments

4) Regional institutions and organizations

5) International bodies

6) Non-governmental organizations (NGOs)

7) The private sector

8) The media (local and international)

9) The scientific community

10) Telephone (fixed or mobile) 
TABLE I

Comparison of Different Communication Channels Used in Disaster Warning [1]

\begin{tabular}{|c|c|c|}
\hline Channel & Benefits & Challenges \\
\hline $\begin{array}{l}\text { Radio and } \\
\text { Television }\end{array}$ & Widespread & $\begin{array}{l}\text { 1) Takes time to get the warnings } \\
\text { 2) Limited use at night }\end{array}$ \\
\hline $\begin{array}{l}\text { Cell } \\
\text { broadcasting }\end{array}$ & $\begin{array}{l}\text { No congestion } \\
\text { Can address a group } \\
\text { simultaneously }\end{array}$ & $\begin{array}{l}\text { 1) Does not reach non-users } \\
\text { 2) Local language problems }\end{array}$ \\
\hline Satellite radio & High reach ability & $\begin{array}{l}\text { 1) Cannot be used to educate masses } \\
\text { 2) Only good for specific points }\end{array}$ \\
\hline Internet/Email & $\begin{array}{l}\text { Interactive } \\
\text { Multiple sources can be checked } \\
\text { for } \\
\text { accuracy of information }\end{array}$ & 1) Not widespread \\
\hline $\begin{array}{l}\text { Amateur/ } \\
\text { Community } \\
\text { radio }\end{array}$ & $\begin{array}{l}\text { Excellent for rural, poor and remote } \\
\text { communities }\end{array}$ & $\begin{array}{l}\text { 1) Not widespread } \\
\text { 2) People lose interest if used only in case } \\
\text { of disaster }\end{array}$ \\
\hline Sirens & $\begin{array}{l}\text { Can be used even at night } \\
\text { Good in rural areas }\end{array}$ & $\begin{array}{l}\text { 1) Maintenance of the system } \\
\text { 2) Cannot disseminate a detailed message }\end{array}$ \\
\hline $\begin{array}{l}\text { Telephone } \\
\text { (fixed and } \\
\text { mobile) }\end{array}$ & Messages delivered quickly & $\begin{array}{l}\text { 1) Problems of authenticity } \\
\text { 2) Does not reach non-users } \\
\text { 3) Congestion }\end{array}$ \\
\hline SMS & $\begin{array}{l}\text { Quick } \\
\text { Messages can be sent to groups }\end{array}$ & $\begin{array}{ll}\text { 1) } & \text { Congestion } \\
\text { 2) } & \text { Does not reach non-users } \\
\text { 3) } & \text { Local language problems } \\
\end{array}$ \\
\hline
\end{tabular}

In the proposed system, we are focusing on telecommunication option for sending early alerts. Though this option has some problems as described in Table 1, we will discuss about some alternatives to solve the problems. In the proposed system, there two modules: 1) Weather server: collects data from google weather api, Bangladesh Space Research and Remote Sensing Organization (SPARRSO [16]) and Bangladesh Meteorological Department [17] and 2) A simple java application for subscriber's mobile device.

The weather server continuously and automatically collects data from the above sources, stores in the database and generates early warning messages for the subscribers. The subscribers have to register the service. Then a simple java application will be installed on subscribers' handset. This java application will send the subscriber's position (longitude and latitude) periodically to the weather server. Weather server will check against its database. If there is any warning message in the database for that location, weather server will send that message through voice call. This voice call will be automated and in Bengali language and contain information about current weather conditions, local warning message, location and path of the nearest shelter center, emergency contact numbers etc. The system will not send SMS as people may not respond while asleep. It will also warn subscribers if his/her location is changing towards a location where there are some alerts are in place. A process flow diagram and a snapshot of the weather server are in Fig. 2 and Fig. 3.

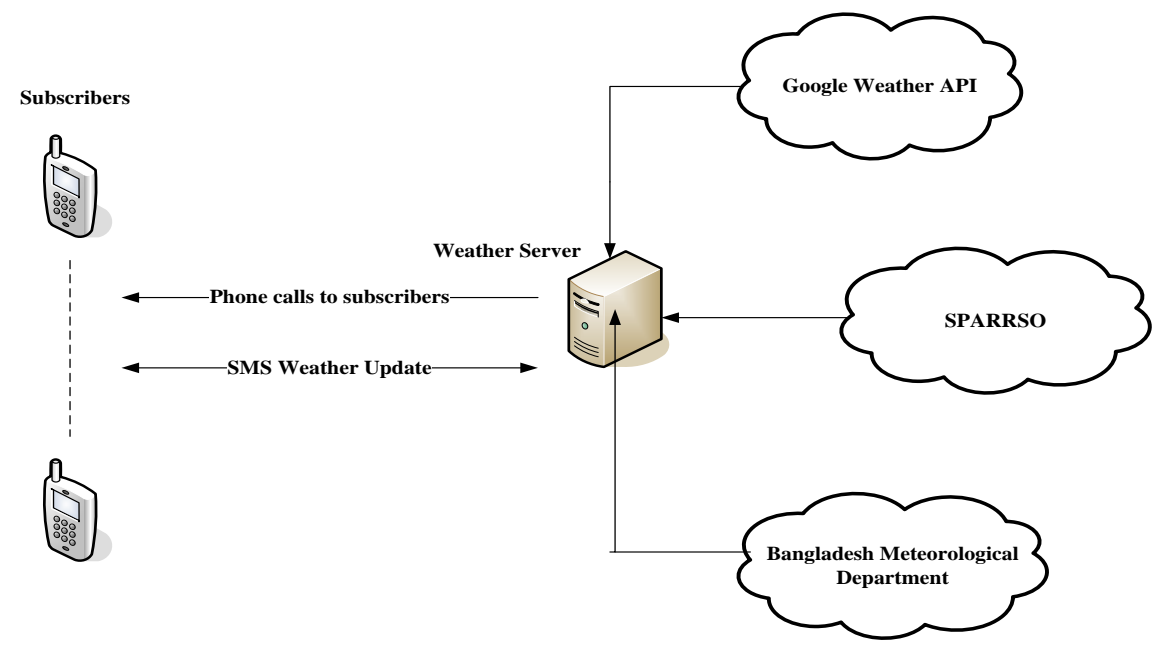

Fig. 2 Process flow diagram of the proposed system 


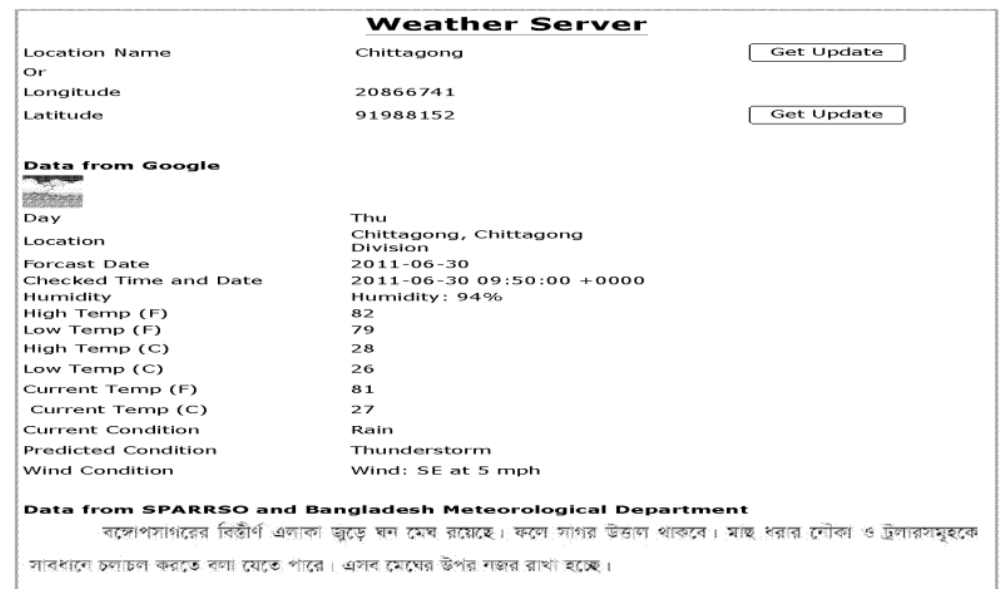

Fig. 3 Proposed weather server

Beside this, any mobile phone user can get the weather update of his/her place simply by sending formatted SMS (send SMS containing text "w") to weather server and this particular service is for all mobile phone users i.e. users do not need to subscribe to know the weather update through SMS. These services will be very helpful for the fishermen of the coastal area, also for the local people and tourists.

\section{Feasibility Analysis And PerformanCe Evaluation}

Most of the people of our country are uneducated. That's why the proposed system will make an automated phone call for sending warning message in local language (Bengali). And for registration, they can go to nearest balance recharge center as they always need to go there for recharging the balance. On the other hand, the setup cost of the weather server is very low. The weather server will be a server computer which will run the core software.

For availing this service, subscribers have to have a java supported handset. In our country, the minimum cost of this type of handset is very low (say 2,000 BDT). So it is possible for everyone at least every family to buy this type of handsets.

The system is currently in the operational testing phase. We tested within Dhaka city and it is working perfectly. The response time is very small as all updated and processed data are stored in database.

This weather server is web module. So anyone can see weather update from the web page.

\section{FUTURE WORKS}

If the telecomm operator can provide their subscribers' cell phone number and their current location, weather server will collect phone numbers and locations from the operators. So people won't need to subscribe this service separately and even memorize anything about the service. Weather server will automatically send warning calls to all subscribers of a danger zone. The telecomm operators won't get direct revenue from this service. But people will buy SIM of the operator who is providing this service and this will generate revenue in other ways. Then it will be more advantageous for the society.

\section{CONCLUSION}

We all know about the recent devastating earthquakes and tsunami in Japan. Thousands of human lives were destroyed. In Bangladesh, the strongest cyclone in the Bay of Bengal named Sidr took place in 2007. The storm caused large-scale evacuations. 3,447 deaths were blamed on the storm. Save the Children estimated the number of deaths to be between 5,000 and 10,000, while the Red Crescent Society reported on November 18 that the number of deaths could be up to 10,000 . International groups pledged US\$95 million to repair the damage, which was estimated at $\$ 1.7$ billion (2007 USD) [18]. It was a huge loss. In this paper, we proposed and developed a weather early warning system to send early alerts to the people. We think this system will help the society very much.

\section{ACKNOWLEDGMENT}

Special thanks to my advisor. I am indebted to him for his valuable commitment of time, conscientious advice, sound guidance, sincere efforts, constant support and encouragement. He allowed me to have freedom and flexibility in my research choices and helped me every step of the way. I whole-heartedly thank him for his trust and confidence in me. 


\section{REFERENCES}

[1] Chanuka Wattegama, ICT for Disaster Management, Asia-Pacific Development Information Programme, 2007.

[2] Dr. Mashury Wahab, Integrated Data Communications and Processing For Early Warning System, The Euro-Southeast Asia Cooperation Forum on ICT research, October 6-7, 2008.

[3] Olaf Neussner, Allen Molen and Thomas Fischer, Using Geoinformation Technology for the Establishment of a Local Flood Early Warning System, Second International Conference of Geoinformation Technology for Natural Disaster Management and Rehablitation, December 01-02, 2008.

[4] Joko Windarto, Flood Early Warning System Develop at Garang River Semarang using Information Technology base on SMS and Web, International Journal Of Geomatics and Geosciences, Volume 1, No 1, 2010.

[5] Shanghai Meteorological Bureau, CMA, Overview of Shanghai Multi-hazard Early Warning system and the role of Meteorological Services, Shanghai 200030, China, 2010.

[6] Brendan Williams, Adequacy of forecasts and early warning systems particularly as they related to the flooding events in Toowoomba, and the Lockyer and Brisbane Valley, Queensland Floods Commission of Inquiry, March 2011.

[7] P. Vanderkimpen, I. Rocabado1, J. Cools, M. El-Sammany and A. Abdelkhalek, FlaFloM-an early warning system for flash floods in Egypt.

[8] Kerry Plowright, Global Multi-Hazard Early Warning System, The Australian Early Warning Network (EWN).

[9] Chai Mui Fatt, Asmadi bin Abdul Wahab, Norhadizah binti Mohd Khalid, Nasrul Hakim bin Hashim, Muhammad Nazri bin Noordin and Mohd Rosaidi bin Che Abas, Tsunami Databases for The National Tsunami Early Warning Centre of Malaysia: Toward The Implementation Plan of Regional Tsunami Watch Providers (Rtwp), Malaysian Meteorological Department.

[10] Rosita Galang and Rosmadinor Mohamad, Utilizing Satellite and Radar Images using Remote Sensing and GIS for Weather Forecasting, Jabatan Meteorology Malaysia.

[11] Kumarenthiran Subramaniam, Ling Leong Kwok and Wan Azli Wan Hassan, Performance of Ensemble Prediction for Malaysian Meteorological Department (MMD) Numerical Weather Prediction (NWP) Model, Jabatan Meteorologi Malaysia.

[12] Summary for Policy Makers, Seismic and Tsunami Hazards and Risks Study In Malaysia, Final Report, January 2009.

[13] Veronica F. Grasso and Ashbindu Singh, Early Warning Systems: State-of-Art Analysis and Future Directions, Draft report, United Nations Environment Programme (UNEP).

[14] Ministry of Science, Technology and Innovation, Malaysian National Report on Tsunami Early Warning System.

[15] EM-DAT: The OFDA/CRED International Disaster Database, http://www.em-dat.net, Université Catholique de Louvain - BrusselsBelgium, 2004.

[16] Bangladesh Space Research and Remote Sensing Organization (SPARRSO), www.sparrso.gov.bd.

[17] Bangladesh Meteorological Department, http://www.bmd.gov.bd

[18] Cyclone Sidr, http://en.wikipedia.org/wiki/Cyclone_Sidr 